\title{
A STUDY ON INTERNAL FIXATION OF COMPOUND FRACTURES OF TIBIA USING INTERLOCKING NAIL WITHOUT REAMING
}

\author{
C. Pradeep Chandra1, K. Chandra Sekhar Rao ${ }^{2}$, A. Krishna Reddy33, Bachu Srinivas ${ }^{4}$
}

${ }^{1}$ Assistant Professor, Department of Orthopaedics, Gandhi Medical College.

${ }^{2}$ Assistant Professor, Department of Orthopaedics, Gandhi Medical College.

${ }^{3}$ Assistant Professor, Department of Orthopaedics, Gandhi Medical College.

${ }^{4}$ Assistant Professor, Department of Orthopaedics, Gandhi Medical College.

\begin{abstract}
As one-third of the tibial surface is subcutaneous throughout its length, open fractures are commonly encountered in this bone. The factors which determine the outcome of these fractures are severity of the injury, indicated by the degree of initial displacement, comminution and soft tissue injury and the damage to the tibial blood supply. In open fractures not only is the endosteal circulation disrupted but also the periosteal circulation, because of periosteal stripping. The various available options of treatment such as conservative short leg or long leg casting, open reduction and internal fixation with plates and screws, intramedullary fixation (Including Ender pins, Intramedullary nails and Interlocking Intramedullary nails with reaming or without reaming) and external fixation techniques have their own advantages and disadvantages. The present study was conducted in the Department of Orthopaedics, Gandhi Hospital, during the period from October 2013 to November 2015, to evaluate the results of internal fixation with interlocking intramedullary nailing without reaming in the treatment of the open fractures of tibia. In our study, we got $91 \%$ good-to-excellent results evaluated by Johner and Wruh criteria. We opine that closed unreamed interlocking intramedullary nailing yields good-to-excellent results in compound diaphyseal fractures of the tibia, as this technique allows a good control over the rotations with axial stability of the fracture, thus maintaining the length of the limb and enabling early joint motion. The endosteal blood supply is also well preserved. These factors help in lowering the rates of infection, malunions and non-unions.
\end{abstract}

\section{KEYWORDS}

Tibial Shaft, Compound Fracture, Unreamed Nailing.

HOW TO CITE THIS ARTICLE: Chandra CP, Rao KCS, Reddy AK, et al. A study on internal fixation of compound fractures of tibia using interlocking nail without reaming. J. Evolution Med. Dent. Sci. 2016;5(45):2797-2800, DOI: 10.14260/jemds/2016/653

\section{INTRODUCTION}

Tibial diaphyseal fractures are one of the commonest long bone fractures encountered by most of the orthopaedic surgeons. Because one-third of the tibial surface is subcutaneous throughout most of its length, open fractures. ${ }^{1}$ are more in tibia than in any other major long bone. Furthermore, the blood supply. ${ }^{2}$ of tibia is more precarious than that of bones enclosed by bulky muscles.

The important factors in the prognosis are amount of initial displacement, degree of comminution and severity of soft tissue injury. ${ }^{3}$ Because of the high prevalence of complications associated with these fractures, management is often difficult and the optimum method of treatment remains a subject of controversy. Among the various modalities of treatment such as conservative gentle manipulation and use of short leg or long leg cast, open reduction and internal fixation with plates and screws, intramedullary fixation (Including Ender pins, Intramedullary nails and interlocking Intramedullary nails with reaming or without reaming) and external fixation techniques, surgeon should be capable of using all these techniques and must weigh advantages and disadvantages of each one and adapt the best possible treatment.

Financial or Other, Competing Interest: None.

Submission 01-04-2016, Peer Review 27-04-2016,

Acceptance 02-05-2016, Published 04-06-2016.

Corresponding Author:

Dr. C. Pradeep Chandra,

Assistant Professor,

Department of Orthopaedics,

Gandhi Hospital,

Secunderabad

Telangana.

E-mail: drpradeepchandra@gmail.com

DOI: 10.14260/jemds/2016/653
The best treatment should be determined by a thoughtful analysis of morphology of the fracture, the amount of energy imparted to the extremity, the mechanical characteristics of the bone, the age and general conditions of the patient and most importantly the status of the soft tissues (The skin, muscle and associated neurologic and vascular structures of the leg).

The goals for the successful treatment of open fractures of tibia are prevention of infection. ${ }^{4}$, achievement of bony union and the restoration of function.

The present study was done in the Department of Orthopaedics, Gandhi Hospital.

During the period from October 2013 to November 2015, to evaluate the results of internal fixation with interlocking intramedullary nailing without reaming in the treatment of the open fractures of tibia. It was done to compare the efficiency of interlocking intramedullary nailing without reaming in treatment of open fractures of tibia with other techniques in terms of time required for union and rate of complications such as malunion, nonunion and infection.

\section{MATERIALS AND METHODS}

The present study was done in the Department of Orthopaedics, Gandhi Hospital.

With compound fractures of tibial shaft which were treated with wound debridement and interlocking intramedullary nailing without reaming during the period from October 2013 to November 2015. All the cases were fresh fractures and were traumatic in nature.

\section{THE CRITERIA FOR SELECTION OF THE CASES}

Inclusion Criteria

1. Age more than 18 years. 
2. Shaft fractures within $4 \mathrm{cms}$ distal to the tibial tuberosity to $4 \mathrm{cms}$ proximal to the ankle joint in tibia, in which the medullary canal was large enough to accept a minimum $8 \mathrm{~mm}$ nail.

3. Open fractures type I, II, IIIA and IIIB according to Gustilo Anderson classification.

\section{Exclusion Criteria}

1. Age less than 18 years.

2. Associated intra-articular fractures of proximal distal tibia.

3. Closed fractures and Gustilo type IIIC fractures.

Twenty four cases were available for evaluation. The duration of follow-up ranged from 6 to 10 months (Average 8 months); 18 were male patients and 6 were female, ranging in age from 18 to 67 years old with an average age of 32 years; 16 were right sided and 8 were left sided tibial fractures. Most of the fractures were caused by high-energy trauma; 16 of the fractures were caused by pedestrian-automobile accidents, 4 by motor cycle accidents, 2 by motor vehicle accidents, 2 by fall from height.

The soft tissue injuries were classified according to the system of Gustilo et al; 8 wounds were type I, 12 wounds were type II, 2 were type IIIA and 2 were type IIIB.

In all the cases, emergency irrigation and debridement of the open fractures was done as soon as the patients come to our casualty. Patients were operated as early as possible once the general condition of the patients was stable and fit for surgery. In most of the cases, surgery was performed in 2-4 days. Our mean operating time was 90 minutes (Range 60 mins to 120 mins). In all cases, midline patellar tendon splitting approach was used for nail insertion. In our study, we used only tubular nails. Efforts were made to obtain definitive coverage of the wound within 7 days. Three patients were done with split thickness skin grafting in the same sitting. Five patients were done with split thickness skin grafting within 7 days after the injury. In two patients, the wound was covered with soleus flap.
All the patients were mobilized post-operatively as early as possible depending upon the fracture stability, general condition and tolerance of the patient; 20 fractures were united within 6 months of injury and 3 cases of delayed union which united within 36 weeks. One fracture with comminution failed to unite (Non-union) 10 months after the injury.

\section{RESULTS}

Most of the patients in our study were operated 2-4 days after trauma, 3 cases were operated less than 8 hours of trauma. In our study, all cases were mobilized with NWB on next day. For most of the patients, PWB was started on 11-20 days postoperatively. In 2 cases PWB was delayed for more than 30 days, 8 patients were commenced to protective FWB at 6 weeks post-operatively. In our study, most of the patients were commenced to protective FWB at 8-12 weeks postoperatively. The time for union ranged from 3-9 months with an average of 5 months; 19 fractures healed before 20 weeks, 4 fractures healed between 21-36 weeks, one fracture failed to unite 9 months after the injury.

In 14 patients, full range of knee motion was achieved by 12 weeks. In 8 cases, more than $80 \%$ of the knee motion was achieved. In 1 case, less than $50 \%$ of ankle motion was seen. In one case minimal valgus angulation was noted and in another case minimal anterior angulation. Shortening less than $1 \mathrm{~cm}$ was seen in two cases; 2 patients developed superficial infections, one in Gustilo type II and another in type IIIA. All the infections were healed with oral antibiotics. One patient developed deep infection in Gustilo type II fracture. He was treated for 6 weeks with IV antibiotics. Locking screws were broken in two cases. None of the nails were broken or were bent.

Detailed analysis of functional results was analysed on the basis of Johner and Wruh criteria, where we found 14 cases (58.33\%) had excellent results, 8 cases had good results $(33.33 \%)$, one had fair $(4.16 \%)$ and one had poor (4.16\%).

\section{CASE 1}

Pre-op

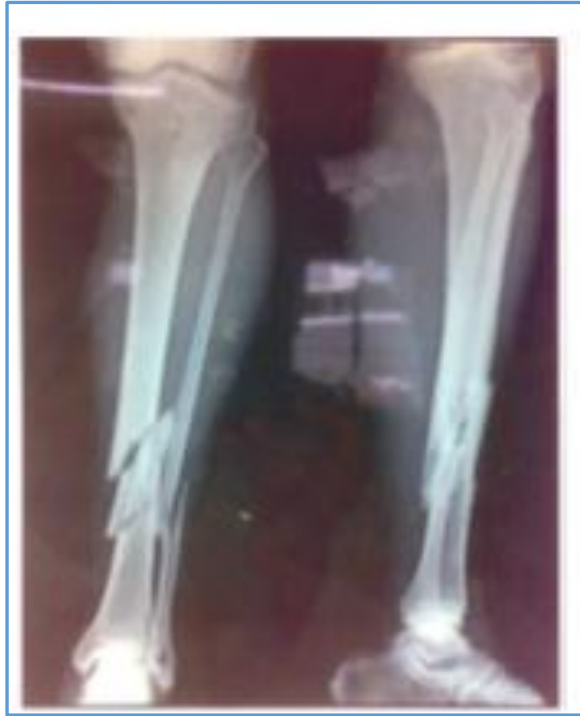

Post-op

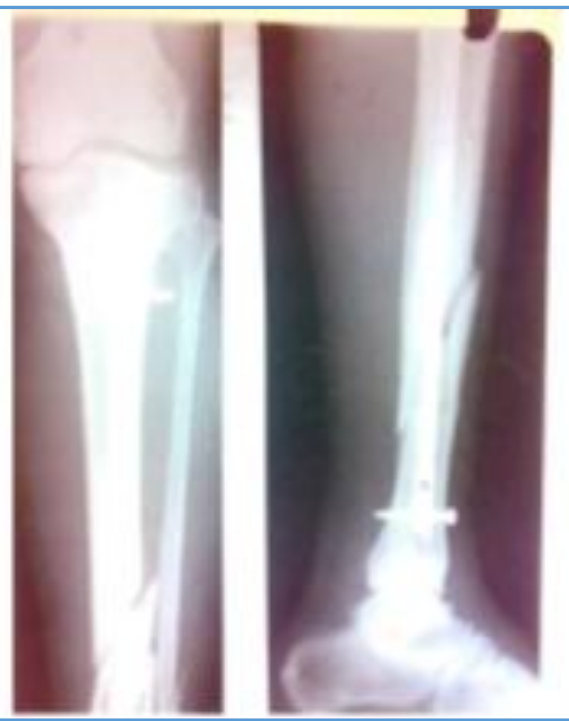

8 mo. Followup

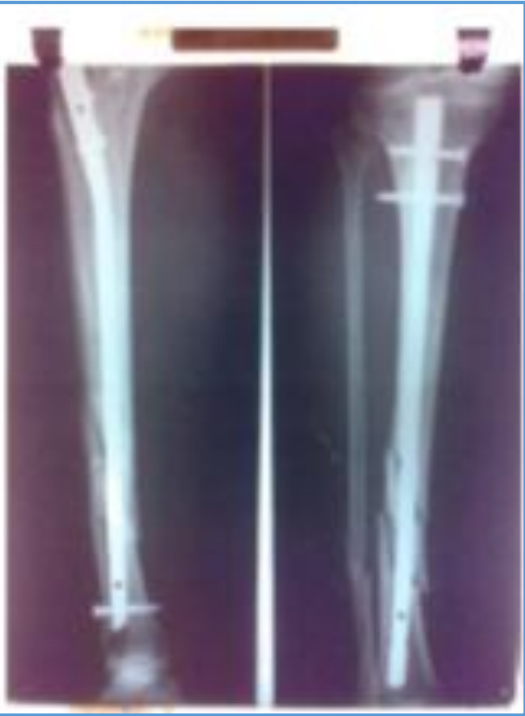


CASE 2

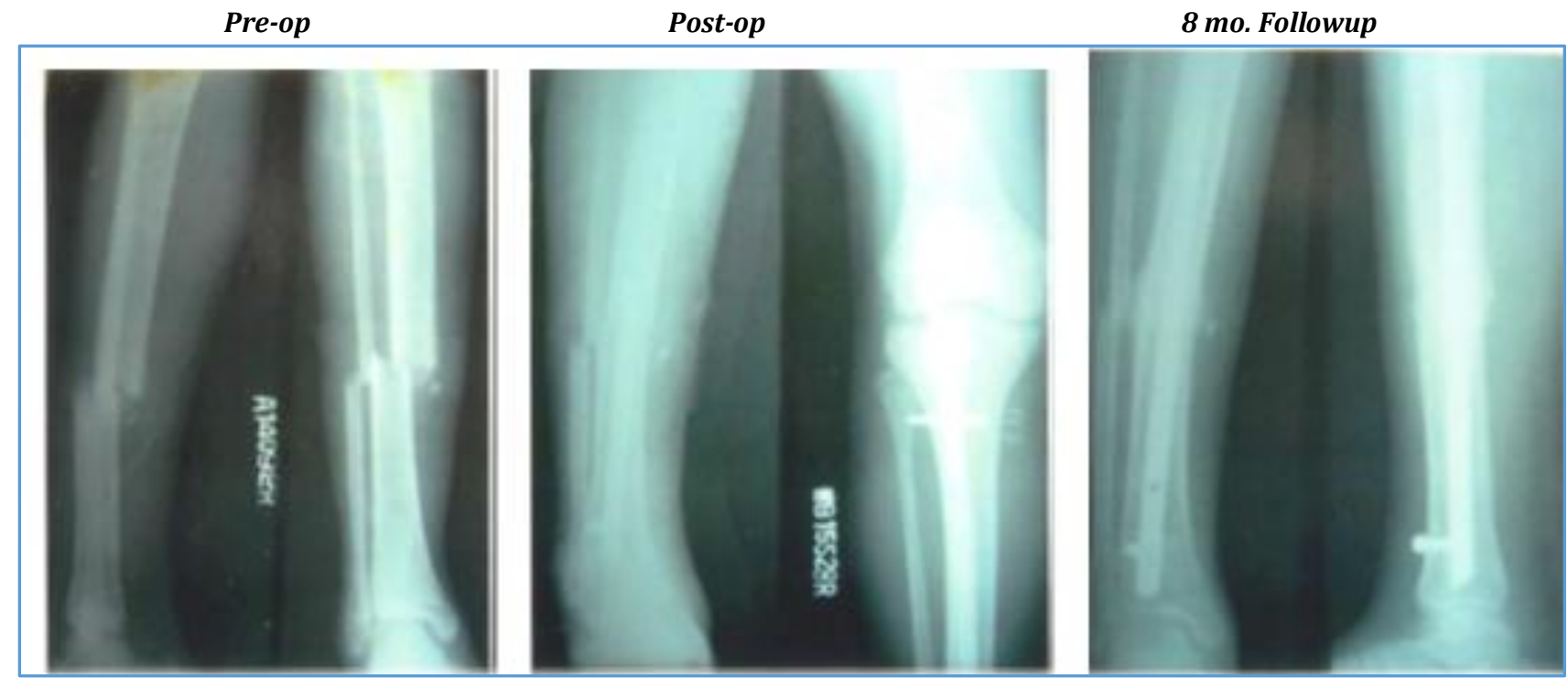

CASE 3

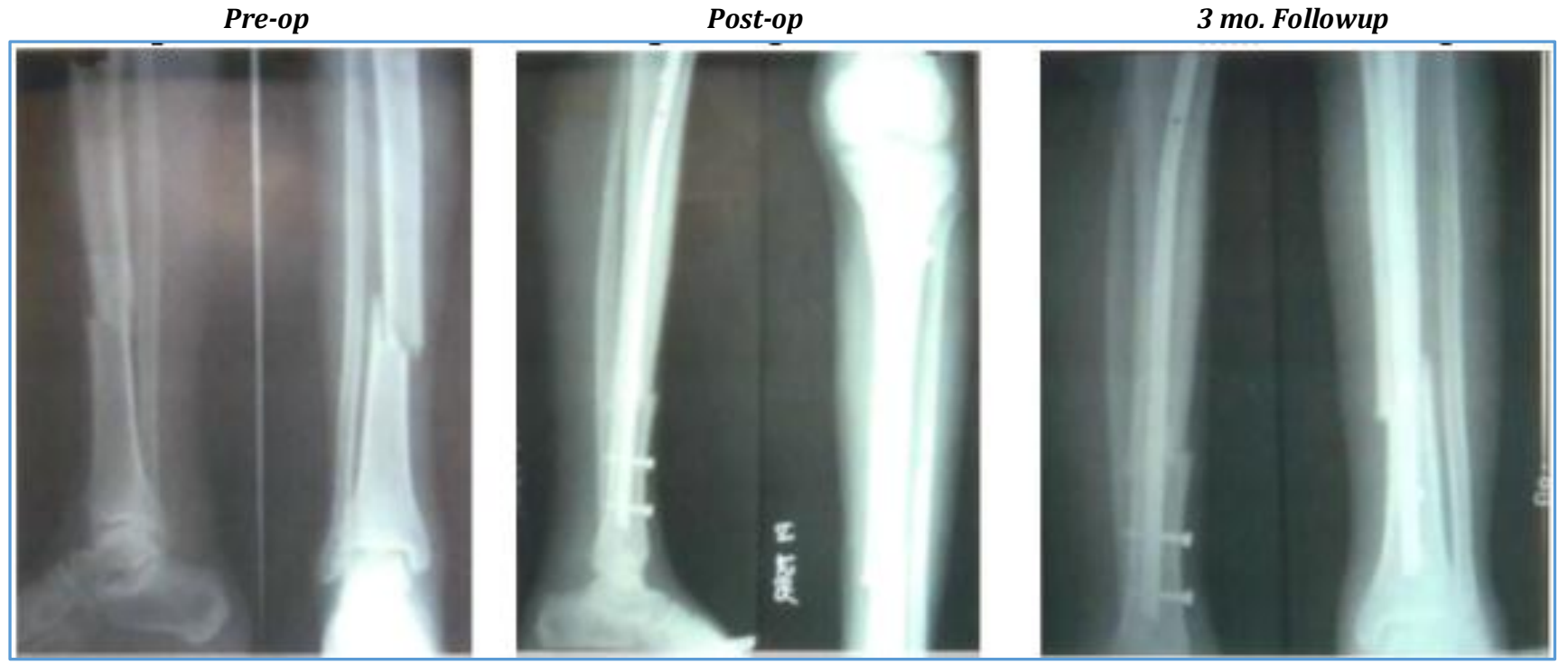

\section{DISCUSSION}

The optimal management of open tibial shaft fractures continues to be a problem with several unanswered questions. ${ }^{5}$ Those fractures usually caused by high energy trauma have numerous problems resulting from the poor soft tissue coverage and limited blood supply to the tibia often resulting in mal-union, non-union and infection. Sometimes even ending up in amputation. Recent improvements in wound coverage techniques and fixation devices have decreased the prevalence of these complications.

There are two major factors, which influence the final outcome of tibial shaft fractures. The first is the severity of the fractures which is indicated by the degree of initial displacement, comminution and soft tissue injury. Accordingly, the more severe the fracture, the higher the rate of complications and the longer the period of healing. The second factor is the damage of the tibial blood supply. In open fractures, not only is the endosteal circulation disrupted but also the periosteal circulation because of periosteal stripping.
Application of a plaster cast has been the most common method of treatment for the fractures of the tibia, but it has several disadvantages like infection and shortening. 6

Plate osteosynthesis provides rigid fixation of an unstable fracture, thereby reducing the problem of non-union. But the stripping of soft tissue required for application of a plate, however, has led to an unacceptable rate of infection in patients who have an open tibial factures. External fixation techniques maintain several advantages in the treatment of severely comminuted open tibial shaft fractures (Grade IIIB and $\mathrm{C}$ ), thus providing early stabilization, improving the survival of injured soft tissues and enabling the mobility of the patient. But even with this technique the chances of malunion, delayed union and non-union are quite significant currently in grade I, II and IIIA open fractures. The use of external fixation has been reduced with the advent of unreamed unlocked nail.

of the various intramedullary devices available, the unreamed.7 unlocked nails such as Ender's nails have produced good results in open tibial fractures, but the implant 
did not adequately stabilize the comminuted or segmental fractures. In a randomized, prospective study comparing external fixation.(8) with Ender nails, the major drawback of Ender's nail fixation is lack of axial control.

Interlocking intramedullary nailing with reaming solves the problem of mal-unions because it provides the ability to control length, angulation and rotation, but are associated with high risk of infection in open tibial fractures. However, reaming results in destruction of vessels in the medullary canal and increases the intramedullary pressure, which leads to infiltration of medullary fat, blood clots into the vascular channels (Embolism). The destruction of endosteal blood vessels along with already compromised vascular supply due to periosteal stripping and soft tissue damage causes considerable bone necrosis, which accounted for higher rates of infection and non-union in open tibial fractures.

Intramedullary nailing without reaming is less damaging to the endosteal blood supply, thereby reducing the rate of infection and nonunion.

Studies have shown that intramedullary reaming disrupts an average of 70 percent of the cortical blood supply, while insertion of a nail without reaming disrupts the blood supply only in the inner third of the cortex. This is especially valuable in the treatment of open fractures, in which the outer cortical blood supply is already damaged by periosteal stripping.

Therefore, closed unreamed interlocking intramedullary nailing combines the most desirable features of external skeletal fixation and of non-locking nailing. Length, alignment and rotations are controlled. The soft tissues are easily accessible. These factors lowered the rates of infection, malunions and non-unions and thus expanded the use of intramedullary nails to fractures near the metaphysis and to those with more severe comminution and soft tissue injury.

In our series twenty (83.33\%) fractures united within 6 months of injury, which is comparable with the other series as well. The delay in union was noticed in 3 patients with severe comminution and extensive soft tissue injury. In the current series, there was one deep infection (4.16\%) in type II open fracture. The incidence of deep infection $(4.16 \%)$ compares favourably with other series reporting rate of $2.4 \%$ to $11.6 \%$. The infection rate using non-reamed locked nails is favourable compared with external fixation (6-14\% deep infection rates) and other methods.

In our series the implant's failure is rarely encountered and locking screws were broken in two cases (8.33\%), but the breakage did not result in any loss of reduction. On the basis of this study, we would like to recommend dynamisation of most statically locked nails at 8-12 weeks if callus is not evident to promote fracture union and to avoid fracture of the interlocking screws. Our results are comparable with other series of studies.

In our series no patient developed fat embolism, compartment syndrome, peroneal nerve palsy and reflex sympathetic dystrophy.

To conclude closed unreamed interlocking intramedullary nailing yields good-to-excellent results in open diaphyseal fractures of the tibia, as this technique allows a good control over the rotations with axial stability of the fracture, thus maintaining the length of the limb and enabling early joint motion, early weight bearing allowing earlier return to work. The endosteal blood supply is also well preserved and the soft tissues are also easily accessible. These factors lowered the rates of infection, malunions and non-unions and thus expanded the use of this technique to fractures near the metaphysis and to those with more severe comminution and soft tissue injury.

\section{REFERENCES}

1. Rhinelander FW. Effects of medullary nailing of the normal blood supply of diaphyseal cortex 1973. Clin Orthop 1998;350:5-17.

2. Rhinelander FW. Tibial blood supply in relation to fracture healing. Clin Orthop 1974;105:34-81.

3. Watson-Jones. Injuries of the leg. In: Wilson IN. ed. Watson Jones fractures and Joint injuries. Bl Churchill Livingstone, New Delhi, Chapter-32, 1998; $6^{\text {th }}$ ed:p387.

4. Bach AW, Hansen ST. Plates versus external fixation in severe open tibia shaft fractures: a randomised study. Clin Orthop 1989;241:89-94.

5. Whittle AP, Russell TA, Taylor JC, et al. Treatment of open fractures of the tibial shaft with the use of interlocking nailing without reaming. J Bone Joint Surg 1992;74(8):1162-71.

6. Whittle AP. Fracture of lower extremity. In: Canale ST, ed Campbell's operative orthopaedic. Mosby, New York, chapter-47, 1998; $9^{\text {th }}$ ed:p2067-94.

7. Charley J. Fractures of the shaft of tibia. The closed treatment of common fractures. Edinburg: Churchill Livingstone 1961;p209-49.

8. Holbrook JL, Swiontiowski MF, Sanders R. Treatment of open fractures of the tibial shaft: ender nailing versus external fixation: a randomized prospective comparison. J Bone Joint Surg 1989;71(8):1231-8. 